\title{
Coronary endarterectomy: technique and results in a case-control study
}

\author{
Endarterectomia de artérias coronárias: técnicas e resultados em estudo com grupo controle
}

André Luiz TYSZKA ${ }^{2}$, Maria Marta de Carvalho CABRAL ${ }^{1}$, Ederval Key HAYASHI ${ }^{1}$, Geraldo Ângelo NOGUEIRA $^{1}$, Marcos Borges MACHADO ${ }^{1}$, Leonardo Monteiro de Castro MACHADO ${ }^{1}$, Armando PROGIANTE ${ }^{1}$, Leila Satomi FUCUDA², Raul D’Áurea MORA ${ }^{1}$

RBCCV 44205-620

\begin{abstract}
:
Objective: Early reports showed a high incidence of postoperative morbidity and mortality after coronary endarterectomy, and its value is still controversial. With technical improvement the role of coronary endarterectomy has been reviewed. In this study we evaluate our results of coronary endarterectomy, and show our strategy for patients with diffuse coronary artery disease.

Method: We retrospectively reviewed 278 patients who underwent coronary artery bypass grafting, between January 2000 and December 2001, separated in two groups. The endarterectomy group - 32 patients $(11.5 \%)$ who underwent coronary endarterectomy and the control group of patients characteristics similar to the first group.

Results: The mean follow-up time was 9.9 months. Both groups only demonstrated a statistical difference in the number of previous myocardial infarctions. The coronary endarterectomy was performed on 38 vessels, $78.75 \%$ in the left coronary system, and $21.05 \%$ in the right system. In the postoperative follow-up no significant differences were detected, but in the coronary endarterectomy group the incidence of intra-aortic balloon pump insertion was higher.
\end{abstract}

Conclusions: We demonstrated that coronary endarterectomy should be used to achieve complete revascularization in patients with diffuse coronary disease, and the results are similar to conventional surgical treatment. A long-term follow up is necessary to demonstrate the future performance of these vessels and grafts.

Descriptors: Coronary disease, surgery. Myocardial revascularization, methods. Endarterectomy.

Resumo:

Objetivo: Os resultados descritos das endarterectomias de artérias coronárias (EAC) refletiam as experiências iniciais e demonstravam uma maior morbidade pós-operatória e mortalidade imediata, tornando seu valor controverso. Com o aprimoramento técnico, o papel da EAC vem sendo revisto. $O$ presente estudo tem como objetivo avaliar os nossos resultados com a EAC e apresentar a nossa conduta frente aos pacientes com doença coronariana difusa.

Método: De um total de 278 pacientes submetidos a revascularização isolada, entre janeiro de 2000 e dezembro de $2001,32(11,5 \%)$ foram endarterectomizados formando o

Work performed in the Hospital Santa Rita de Maringá. Maringá, PR, Brazil.

1 Cardiology Department of the Hospital Santa Rita.

2 Heart Surgery Department of the Hospital Santa Rita.

Correspondence address:

André Luiz Tyszka.

R. Lopes Trovão, 151, s1.

Maringá, PR,

Brazil.

CEP 87014-080.

Tel. (44) 225-5777. 
grupo EAC. O grupo controle foi formado por pacientes com características semelhantes a cada paciente do primeiro grupo.

Resultados: O tempo médio de acompanhamento foi de 9,9 meses. Os dois grupos demonstraram diferença estatística quanto ao número de infartos prévios. Foram realizadas 38 endarterectomias, $\mathbf{7 8 , 7 5 \%}$ nos ramos coronarianos esquerdos e $21,05 \%$ nos ramos coronarianos direitos. No acompanhamento pós-operatório, não se encontrou diferença significativa entre as variáveis estudadas de morbimortalidade, embora uma maior utilização de balão intra-

\section{INTRODUCTION}

Endarterectomy is the removal of the atheromatous plaque, dissecting and separating the external media and adventitia layers, thus restoring the lumen to the artery. In patients with diffuse coronary disease, characterized by long segments impaired by atherosclerosis, endarterectomy of the coronary arteries (ECA) is often necessary to perform complete coronary artery bypass grafting (CABG) or to facilitate anastomosis of seriously calcified arteries.

Diffuse coronary disease can make adequate surgical treatment difficult or even prevent it totally. In these cases conventional CABG does not supply an adequate flow through the entire vessel, resulting in incomplete CABG [1]. Incomplete $\mathrm{CABG}$ does not affect the immediate mortality rate, but the incidence of arterial reoperations with significant obstructions in vessels, which irrigate the viable myocardium, negatively affects long-term cardiac events. These patients have greater recurrence of angina, worse performance in stress tests and a greater work absenteeism rate and require a greater number of re-interventions, besides the better survival rate of completely grafted patients $[2,3]$.

The preliminary results with ECA reflect the experience of the 60 s and 70s and demonstrate a greater morbidity and mortality in the immediate post-operative period, making its merit controversial [4]. With technical improvements and a greater operative indication for patients with diffuse coronary atherosclerotic impairment, the role of endarterectomy is being reassessed [1,5].

This study aimed at evaluating the results of ECA in our aórtico no grupo EAC tenha sido observada.

Conclusões: Demonstrou-se que a EAC deve ser aplicada aos pacientes com doença coronariana difusa, visando uma revascularização miocárdica completa, com resultados comparáveis aos pacientes submetidos a operação convencional. $O$ acompanhamento em longo prazo irá determinar o comportamento destas artérias e de seus enxertos.

Descritores: Coronariopatia, cirurgia. Revascularização miocárdica, métodos. Endarterectomia.

department and to report on our therapeutic conduct with patients suffering from diffuse coronary disease.

\section{METHOD}

In the period from January 2000 to December 2001, 278 patients were submitted to isolated CABG in the Santa Rita Hospital by the Instituto Coração de Maringá. Of this total two sub-groups were defined: Group 1 - denominated as ECA Group, was formed of $32(11.5 \%)$ patients in whom at least one coronary endarterectomy was performed. Group 2 - the Control Group, was formed by an equal number of patients from the same department operated on within the same month and year and with similar characteristics in respect to gender, age, number of grafts and myocardial function as the Group 1 patients. The data of both groups was retrospectively reviewed using the patients' records and when this was insufficient the assistant surgeons and/ or patients were contacted. In February 2002, all the patients were contacted by telephone and information was obtained through the responses to a pre-established questionnaire. The survival, long-term cardiac events (re-interventions new admission in hospital, new hemodynamic studies or angioplasties, acute myocardial infarction or reoperation) and classification of chest angina (Canadian Class) and heart failure (NYHA class) were investigated.

The mean follow-up period was 9.9 months (range of 2 to 26 months). These data were submitted to actuarial analysis to determine the long-term survival. The two groups did not show statistical difference in relation to age, gender, 
risk factors and ventricular function, however there was a statistical difference in respect to the number of previous infarctions as is demonstrated in Table 1 with the preoperative data from the two groups.

Table 1. Pre-operative data:

\begin{tabular}{lccc}
\hline Characteristics & Endarterectomy n=32 & Control n =32 & p-value \\
\hline Age (Mean), variation & $(62.47) .37-81$ & $(63.1) .44-76$ & 0.8 \\
Male gender & $29(90.6 \%)$ & $29(90.6 \%)$ & \\
risk factors & & & \\
Diabetes Mellitus & $10(31.25 \%)$ & $9(28.12 \%)$ & \\
Hypertension & $25(78.12 \%)$ & $10(31.25 \%)$ & \\
Smoking & $17(53.12 \%)$ & $12(37.5 \%)$ & \\
Hypercholesterolemy & $9(28.12 \%)$ & $5(15.62 \%)$ & \\
Familiar history & $16(50 \%)$ & $14(43.75 \%)$ & \\
previous AMI & $21(65.62 \%)$ & $5(15.62 \%)$ & 0.035 \\
previous Angioplasty & $3(9.4 \%)$ & $3(9.4 \%)$ & \\
EF <30\% & $15(46.87 \%)$ & $6(18.75 \%)$ & 0.144 \\
\hline
\end{tabular}

Legend: IAM= acute myocardial infarction; $\mathrm{EF}=$ ejection fraction.

\section{Surgical Technique}

All the operations were performed with the help of cardiopulmonary bypass (CPB), utilizing a membrane oxygenator (Braile - Biomédica, São José do Rio Preto-SP), using surgical techniques to obtain the grafts, to install and maintain the $\mathrm{CPB}$ and myocardial protection as previously described [6,7].

All endarterectomies were performed manually, using the closed method, followed by reconstruction with anastomosis with pre-defined grafts. The ECA was performed when localized conditions impeded an adequate distal flow, that is, total occlusion, distal diffuse disease or multi-segmental disease; or when a calcified or severely dense plaque ruptured, making anastomosis difficult or obstructing the flow. Usually the 5 to $10-\mathrm{mm}$ arteriotomy was lengthened only if complete removal of the plaque was not possible. Very delicate homeostatic forceps (figure 1) were used to develop a plane between the media lamina and the atherosclerotic plaque. With gentle traction, the plaque was removed trying, with the help of anatomic forceps (contra-traction), cause destruction of the arterial wall, facilitating the removal of the largest segment of plaque. Much attention was paid to the complete removal of the distal segment, proximal traction of the plaque was avoided mainly in the interventricular branch due to the risk of proximal dissection and the occlusion of a wide septal branch, oblique branches or even of the circumflex branch. None of the cases required a second arteriotomy distal to the first. In one patient there was a need to immediately review the endarterectomy and the anastomosis of the left internal thoracic artery to the anterior interventricular branch had to be redone.

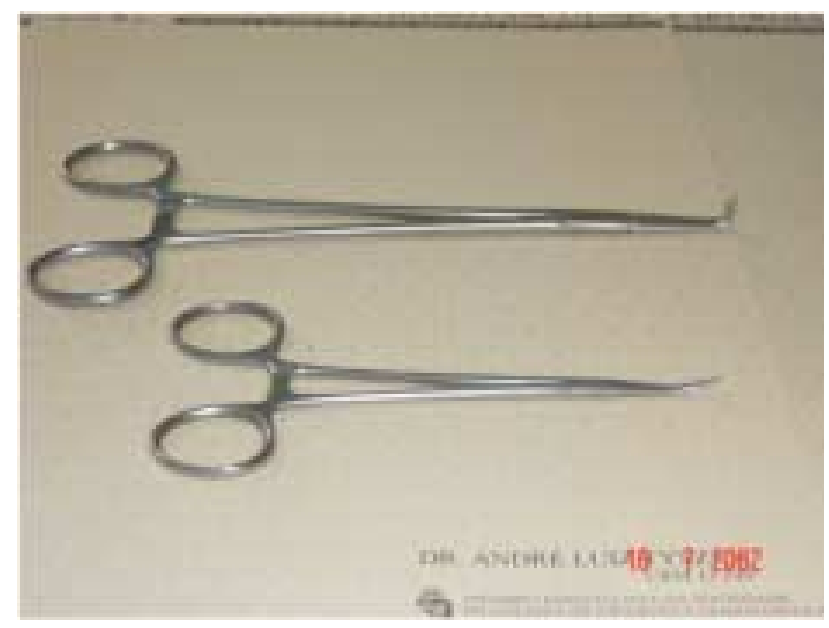

Fig. 1 - Photograph of the instruments used for the removal of the atherosclerotic plaque.

All the patients were referred to the heart surgery postoperative unit where they were hemodynamically monitored. ECGs were performed on arrival in the unit, which were repeated if the results of the first ECG were altered or if the patient presented with any type of hemodynamic deterioration and routinely every morning during their stay in the unit and on the day of hospital release. Transoperative or post-operative infarction was defined as any new 'Q' wave not present on the pre-operative ECG, in the presence of a persistent intraventricular conduction defect or a progression loss of the ' $\mathrm{R}$ ' wave in the precordial derivations. Serial measurements of CK-MB were not routinely obtained.

All the patients received from the first post-operative day for three months acetylsalicylic acid $(200 \mathrm{mg})$ and a derivative of teinopiridin (500 mg ticopidine or $75 \mathrm{mg}$ clopidogrel) via oral aiming to prevent acute thrombosis at the graft and in the endarterectomized artery.

\section{Statistical analysis}

The nominal data were analyzed using the chi-square test and Fisher's exact test. Continuous data were analyzed using the student T-test. Survival curves were calculated by the Kaplan-Meier method. A statistical significance was defined by a p-value of less than 0.05 (Software: Statistical Calculus for Windows V.1.8 - developed by Braile and Godoy). 


\section{RESULTS}

Thirty-eight endarterectomies were performed in 32 patients (1.18 endarterectomies/patient) as $15.62 \%$ of the patients required multiple endarterectomies. Of the 38 endarterectomies, $78.95 \%$ were performed in the left coronary arteries and $21.05 \%$ were performed in the right coronary branches. In the ECA group the anterior interventricular branch was grafted in $90.6 \%$ of the cases with the left internal thoracic artery (LITA), and when this branch required endarterectomy it could be grafted with the LITA in $81.25 \%$ of the times. The numbers of grafts and endarterectomies are shown in Table 2.

Table 2. Operative data:

\begin{tabular}{rccc}
\hline Data / variables & ECA Group & Control Group & P-value \\
\hline Number of grafts (m) & 3.97 & 3.65 & 0.175 \\
X2 & 2 & 4 & \\
X3 & 6 & 10 & \\
X4 & 15 & 12 & \\
X5 & 9 & 5 & \\
X6 & 0 & 1 & \\
\hline Utilization of LITA (\%) & 90.6 & 100 & \\
\hline Number of endarterectomies (m) & $38(1.18)$ & 0 & \\
anterior descending branch & $16(42.10 \%)$ & & \\
diagonal branch & $4(10.52 \%)$ & & \\
left marginal branch & $10(26.31 \%)$ & & \\
posterior descending branch & $6(15.78 \%)$ & & \\
right coronary artery & $2(5.26 \%)$ & & \\
\hline
\end{tabular}

$\mathrm{m}=$ mean by patient; ATIE $=$ left internal thoracic artery.

Early morbidity and mortality are demonstrated in Table 3. No significant difference was found between the two groups in relation to hospital complications. We emphasize the greater use of intra-aortic balloon in the endarterectomized patients, although without statistical significance $(\mathrm{p}$-value $=0.148)$. There were no intra-operative mortalities in either group. In the ECA group there was a hospital death - a sudden death on the first post-operative day, and a late death (in the $20^{\text {th }}$ post-operative month) which was not related to heart problems, in an 82-year-old patient suffering from pancreatic cancer. The actuarial survival curve at 26 months follow-up is shown in Figure 2.

During this follow-up period, $87.5 \%$ of the ECA group were in Canadian Class 1 and $5.55 \%$ in Canadian Class II. One patient of the control group presented with precordialgia and was readmitted and, although there was no electrocardiographic evidence of acute myocardial infarction, a cardiac catheterism was repeated which demonstrated occlusion of a small left marginal branch. The other patients of the control group remained asymptomatic from the cardiovascular point of view. No other patient
Table 3. Post-operative data:

\begin{tabular}{lllc}
\hline Data / variables & ECA Group & Control Group & P-value \\
\hline Use of intra-aortic Balloon (\%) & $7(21.9 \%)$ & $2(6.25 \%)$ & 0.148 \\
Renal failure (\%) & $3(9.37 \%)$ & $1(3.12 \%)$ & 0.61 \\
Respiratory failure (\%) & $1(3.12 \%)$ & $2(6.25 \%)$ & 1.0 \\
Post-operative AMI (\%) & $1(3.12 \%)$ & $2(6.25 \%)$ & 1.0 \\
Early mortality (\%) & $1(3.12 \%)$ & 0 & 1.0 \\
Late mortality (\%) & $1(3.22 \%)$ & 0 & 1.0 \\
\hline
\end{tabular}

$\mathrm{m}=$ mean; $\mathrm{AMI}=$ acute myocardial infarction.

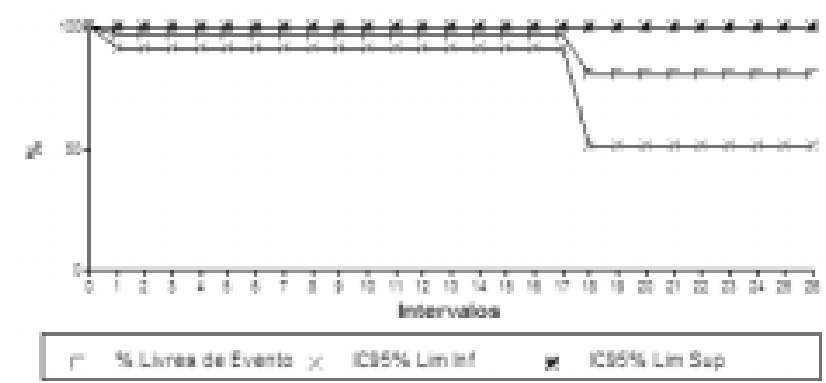

Fig. 2 - Actuarial survival curve of endarterectomy patients over 26 months.

presented with clinical indications of needing a new catheterism. The other patients from both groups were not readmitted to hospital for cardiovascular motives and did not present any history of new acute myocardial infarctions.

\section{COMMENTS}

ECA was one of the first procedures of direct coronary artery bypass grafting. Charles Bailey was the pioneer to perform closed endarterectomy in humans on October 29th 1956 without the use of CPB [8]. In 1958, Senning et al. reported their experiences with endarterectomy with direct visualization of the plaque and reconstruction with segments of internal thoracic artery. The initial results were very inconsistent, only becoming satisfactory with the combination with venous and arterial grafts [9].

The exact incidence of diffuse coronary disease is unknown. The percentage of non-grafted coronaries in the CASS - Coronary Artery Surgery Study - was $4.9 \%$ of the patients [10]. As can be seen in Table 4, the incidence of ECA varies between the different cardiovascular surgery departments - from $1 \%$ to $50 \%$, depending on the experience and the interest of the department. In Brazil, in 1994, Salerno et al. [11] divulged their experience and 3.9\% of their grafted patients were also endarterectomized, with an average age of 58.9 years and a predominance of men $(90 \%)$. 
As is also demonstrated in Table 4, the most common artery to be submitted to ECA is the right coronary. This is the main difference with our study where the prevailing artery is the left coronary branch $(78.75 \%)$. This must be due to the conduct of the department to preferentially graft the posterior interventricular branch and not to routinely approach the right coronary artery which, because of the specific characteristics of its walls, are more frequently affected by a significant thickening and calcification.

Table 4. Experience of departments with coronary endarterectomy.

\begin{tabular}{llllll}
\hline Author, year & ECA \% & RC \% & Mortality & PO AMI & Men \\
\hline Cooley, 1971 [4] & $38 \%$ & $?$ & $7.7 \%$ & $?$ & $?$ \\
Qureshi, 1985 [12] & $42 \%$ & $72 \%$ & $4 \%$ & $12 \%$ & $88.4 \%$ \\
Livesay, 1986 [13] & $12.4 \%$ & $83 \%$ & $4.4 \%$ & $5.4 \%$ & $90 \%$ \\
Trehan, 1993 [14] & $12.4 \%$ & $62.9 \%$ & $?$ & $?$ & $?$ \\
Salerno, 1994 [11] & $3.9 \%$ & $61.8 \%$ & $4.5 \%$ & $9.0 \%$ & $90 \%$ \\
Sundt,1999 [15] & $2.3 \%$ & $?$ & $?$ & $?$ & $?$ \\
Brenowitz, 1988 [5] & $50 \%$ & $51.7 \%$ & $8.3 \%$ & $10 \%$ & \\
Ferraris, 2000 [16] & $?$ & $62.9 \%$ & $?$ & $?$ & $80 \%$ \\
Asimakopoulous, 1999 [17] & $4.1 \%$ & $51.5 \%$ & $3.6 \%$ & $5.4 \%$ & $84 \%$ \\
Gill, 1998 [18] & $21.9 \%$ & $?$ & $4.0 \%$ & $21.6 \%$ & $81 \%$ \\
Total & $20.77 \%$ & $63.68 \%$ & $5.21 \%$ & $10.56 \%$ & $85.56 \%$ \\
Tyszka, 2003 & $11.5 \%$ & $21.05 \%$ & $3.12 \%$ & $3.12 \%$ & $90.6 \%$ \\
\hline
\end{tabular}

Legend: ? - Data unavailable; $\mathrm{ECA}=$ endarterectomy; $\mathrm{RC}=$ right coronary artery; $\mathrm{PO}$ AMI = post-operative acute myocardial infarction.

The percentage of endarterectomized patients $-11.5 \%$, is similar to the average of other departments. This may not seem high, but analyzing the low incidence of endarterectomies on right coronary arteries $(5.26 \%)$, where the need is generally greater, mainly in patients more affected by diffuse arteriosclerosis. From this we conclude that this percentage could be higher, if the same principles to treat the right coronary artery were utilized or considering only the left coronary branches. The same reasoning can be applied to the multiple endarterectomies, which vary for department to department from 5.5\% published by Salerno et al. [11], to $63.9 \%$ as presented by Gill et al. [18]. In this study the rate was $15.62 \%$ of the cases.

ECA is indicated when the coronary vessel is so severely affected by arteriosclerotic disease that conventional surgery is inadequate, where the principal indications summarized by Trehan \& Mishra [14] are reported below:

Indications for coronary endarterectomy:

- Multiple obstructions in the same coronary artery;

- Obstruction of the main vessel and its lateral branches;

- Diffusely diseased artery;

- Separation of the plaque during anastomosis;

- The calcified plaque impeding suturing;

- Occlusion along the entire length of the artery.

ECA can be scheduled, before the arteriotomy, or when necessary after the arteriotomy. Although the atherosclerotic involvement pattern can be predicted by analysis verified by coronary cineangiography, prevision of the necessity of performing ECA is rarely possible, as in the majority of cases it is determined during surgery. ECA is more commonly performed manually, using a closed or open technique. It can also be made mechanically with carbon dioxide or by laser with similar results [13]. Reconstruction of the vessel wall can be by direct suturing (currently utilized), with a venous patch (very rare) or followed by anastomosis with a venous or arterial graft, the widely preferred method.

The technique recommended, according to the above, is the closed manual technique. Reconstruction was always achieved by anastomosis with a venous or LITA graft, when the treated artery was the anterior interventricular branch. The open technique is simple as it does not require special materials, does not have risks of fracture of the plaque and it is easy to treat the coronary branches. However, it involves longer $\mathrm{CPB}$ and aortic clamping times than the closed technique and still the reconstruction of the arterial lumen is more work requiring a long venous patch and making the use of the internal thoracic artery difficult. This procedure was always performed with the help of CPB, however, recently, with the re-emergence of minimally invasive surgeries, ECA without CPB has again been the motive for publications with favorable initial results [19].

Histologically endarterectomy involves dissection and resection of the internal elastic slide of the media layer, leaving only the external elastic slide and the adventic layer of the vascular wall [20]. Walley et al. [21] studied the histologic evolution of these arteries and described that in the first seven days, in patients who do not suffer from thrombosis in the immediate post-operative period, the vessels do not show significant changes. In the subsequent days, the formation of fibrous mural thrombi and platelets, which tend to be organized by a vascularization process and growth of spindle cells, can be expected in bare areas. At the end of 50 days, there is a deposit of collagen and reconstruction of a concentric and uniform luminal layer. The presence of significant stenosis (more than $70 \%$ ) was 
seen in $46 \%$ of the patients who had undergone surgery more than five years before. The atherosclerotic plaque was generally insignificant and stenosis was mainly due to an exaggerated recovery response, more typically concentric. There was no evidence of aneurysms in the vessel.

Because of the greater risk of acute thrombosis after endarterectomy, it is important to consider the role of medicinal therapy in its prevention at the graft and in the endarterectomized artery. Livesay et al. [13] stressed a program of aspirin and Dipiridamol for all these patients which was supported by Chesebro et al. [22], while other such as Dumanian [23] and Ferraris et al. [16] utilized warfarin for 3 months due to the limited antithrombotic effect of aspirin. Gill et al. [18] used heparin intravenously for 48 hours before starting oral therapy. Antiplatelet therapy is being developed and the efficiency of the combination of AAS with tienopiridin derivatives (ticlopidine and clopidogrel) is still to be determined. Initial results demonstrate the same efficiency for both ticlopidine and clopidogrel with the advantage that the latter presents a lower risk of thrombocytopenia and cutaneous alterations [24].

There is still no consensus for the use of ECA due to the lack of randomized studies and contradictory results. While some surgical teams are more liberal, others only recommend it in carefully selected cases. Gol et al. [25] discouraged ECA for right coronary arteries and suggested that plasty with a saphenous patch is a better option, but other authors presented favorable results and, frequently, comparable to conventional grafting [26]. Alternative techniques are also recommended for the treatment of patients with diffuse coronary disease, such as the multiple sequential anastomoses "jumping" as the choice procedure for the revascularization of a diffusely affected anterior intraventricular branch as suggested by Alamanni et al. [27].

Additional to the selected technique, the results after ECA depend on a good functional state of the employed graft and the proliferative response of the surrounding tissue of the endarterectomized vessel. The use of arterial grafts in conjunction with techniques that diminish the response of the vascular wall to the cellular injury, such as the use of new anticoagulants, plaque stabilizers, plaque receptor modifiers, among others, may minimize or even prevent early and late restenosis, both of the graft and the coronary artery itself. When the affected artery was the anterior ventricular branch, utilizing closed endarterectomy this coronary artery could be grafted using the internal thoracic artery in $81.25 \%$, which is important in the determination of its permeability over the short term [26]. Mills [28] reviewed other technical aspects of ECA that are important for the success of the procedure, in particular the appropriate shape and size of the instruments used.
ECA is not appropriate for all patients with diffuse and extensive atheromatous. Generally women are less endarterectomized, as was noted by all authors, probably due to the smaller length and caliber of their arteries. The left circumflex system is more difficult to be endarterectomized due to its location in the atrioventricular duct [13].

Loop [1] in 1988, commenting in an editorial about the re-emergence of ECA, concluded that this is currently a technique with beneficial potential due to three reasons: 1) better myocardial protection allows a more meticulous dissection; 2) the success of ECA requires the complete extraction of the atherosclerotic plaque and 3) the medicinal prevention of arterial thrombosis probably improves the efficiency of the endarterectomized vessels.

The long-term benefits were determined by Livesay et al. [13] who studied over a 14-year follow up period 27,095 patients, of whom 3369 (12.4\%) underwent associated endarterectomies. They demonstrated that long-term survival ten years after endarterectomy $(67 \%)$ was very similar to patients submitted to only revascularization (74\%). The survival at five years was reported as statistically comparable by Miller et al. [26], showing that the long-term benefits can be extended to CABG patients with diffuse arterial disease.

The risks of cardiac complications after endarterectomies are well established. The greatest incidence, that of transoperative infarction, was observed in all studies with varying frequencies, but this is reducing as the myocardial protection techniques improve and with the increased experience of the surgical teams $[26,28]$. On the other hand, not always the infarcted area corresponds to the endarterectomized artery. Gill et al. [18] who had a high incidence of infarction in this group of patients $(21.6 \%)$ found that only in $6.5 \%$ the infarction was related to the endarterectomized artery. And even when the infarcted area corresponds to the endarterectomized artery, this not always indicates that the graft was necessarily occluded. Qureshi et al. [12] observed that only $39 \%$ of the grafts for the infarcted areas were occluded. The occlusion of intramyocardial branches, distal embolization or the temporary lack of equilibrium between blood supply and demand may be responsible for the rest of the acute ischemic episodes. In cases where myocardial infarction occurred with the overt graft, there was no deleterious effect for the global functioning of the left ventricle.

\section{CONCLUSIONS}

Although the number of patients studied is still small, the use of a control group gave us a better homogenization of the sample and assisted in the formulation of conclusions. As the 
results are comparable between the two groups, the conventionally grafted and endarterectomized patients, Important aspects of this technique should be emphasized:

1. The utilization of the closed manual technique, with appropriate instruments was seen to be safe and efficient in the removal of atherosclerotic plaque involved in the principal obstruction.

2. Reconstruction of the anterior interventricular branch should, when possible, be performed with an arterial graft.

3. The lowest incidence of endarterectomy of the right coronary artery, due to the greater approach in the posterior interventricular branch, in general, less affected by the atherosclerotic process, may have a positive influence on the final results.

4. The routine use of new platelet anti-aggregates, such as tienopiridin derivatives, might reduce the incidence of thrombosis in the acute phase after endarterectomy. The utilization of anti-inflammatory drugs to reduce scarring proliferation in the later stage is still not completely known.

The benefits initially obtained should be analyzed during follow-ups of these patients over the long term to elucidate definitive conclusions about this type of approach. Other studies using a larger casuistic should be considered to gain more experience from this surgical technique, thus allowing more liberty in its use.

\section{ADDENDUM}

A total of 118 patients underwent revascularization between January 2002 and November 2002 after sending this study for publication, of whom 14 (11.86\%) required endarterectomies, performed using the same surgical technique by the same surgeon. The pre-operative characteristics were similar to the study group, only differentiated by the greater percentage of endarterectomies performed in women (42\%). Similarly, there was a predominance of endarterectomies in the left coronary branches $(83.33 \%)$ and in $90 \%$, arterial grafts were used. Of these patients, two required extensive endarterectomies of the anterior interventricular branch as is illustrated in Figure 3.

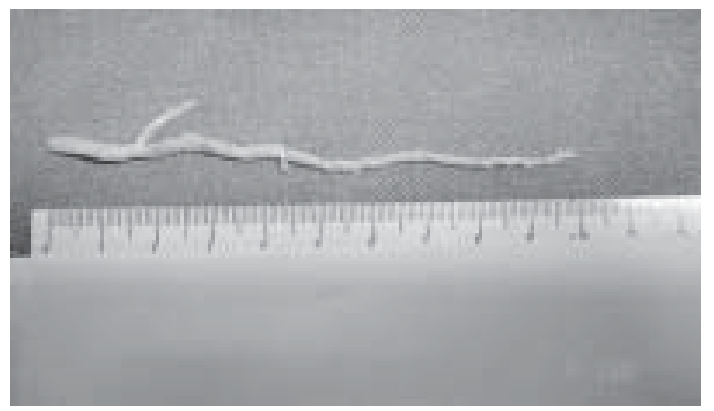

Fig. 3 - Illustrative photograph of the extensive endarterectomy of the anterior interventricular branch performed using the described technique.
In one patient two arteriotomies were used for the complete removal of the plaque, with the reconstructed artery and two sequential anastomoses using the left internal thoracic artery. An acute myocardial infarction complicated by apical interventricular communication with slight hemodynamic repercussion, which was treated clinically, was observed as a post-operative in-hospital complication.

\section{BIBLIOGRAPHIC REFERENCES}

1. Loop FD. Resurgence of coronary artery endarterectomy. J Am Coll Cardiol 1988; 11:712-3.

2. Lawrie GM, Morris Jr GC, Silvers A, Wagner WF, Baron AE, Beltangady SS et al. The influence of residual disease after coronary bypass on the 5-year survival rate of 1274 men with coronary artery disease. Circulation, 1982; 66:717-23.

3. Jones EL, Craver JM, Guyton RA, Bone DK, Hatcher Jr. CR, Riechwald N. Importance of complete revascularization in performance of the coronary bypass operation. Am J Cardiol $1983 ; 51: 7-12$

4. Cooley DA, Hallman GL, Wukasch DC. Myocardial revascularization using combined endarterectomy and vein bypass autograft: technique and results. Int Surg 1971; 56:373-80.

5. Brenowitz JB, Kayser KL, Johnson WD. Results of coronary artery endarterectomy and reconstruction. J Thorac Cardiovasc Surg 1988; 95:1-10.

6. Tyszka AL, Fucuda, LS, Tormena EB, Campos ACL. Obtenção da veia safena magna através de acesso minimamente invasivo para revascularizações miocárdicas. Rev Bras Cir Cardiovasc 2001;16: 105-13.

7. Tyszka AL, Fucuda LS. O uso da artéria torácica interna no idoso: indicações e resultados imediatos. Rev Bras Cir Cardiovasc 2001; 16:269-74.

8. Bailey CP, May A, Lewman WM. Survival after coronary endarterectomy in man. JAMA 1957; 164:641-6.

9. Mueller RL, Rosengart TK, Isom OW. The history of surgery for ischemic heart disease. Ann Thorac Surg 1997; 63:869-78. 
10. CASS: Principal investigators and associates, Coronary Artery Surgery Study (CASS): a randomized trial of coronary artery bypass surgery - survival data. Circulation 1983; 68:939-50.

11. Salerno PR, Dinkhuysen JJ, Chaccur P, Abdulmassih Neto C, Santos MA, Souza LCB et al. Técnica e resultados da endarterectomia de artéria coronária. Rev Bras Cir Cardiovasc 1994; 9:152-8.

12. Qureshi SA, Halim MA, Pillai R, Smith P, Yacoub MH. Endarterectomy of the left coronary system: analysis of a 10year experience. J Thorac Cardiovasc Surg 1985; 89:852-9.

13. Livesay JJ, Cooley DA, Hallman GL, Reul GJ, Ott DA, Duncan JM et al. Early and late results of coronary endarterectomy: analysis of 3369 patients. J Thorac Cardiovasc Surg 1986;92:649-60.

14. Trehan N, Mishra A. Endarterectomy complex coronary reconstructions. In: Buxton B, Frazier OH, Westaby S. Ischemic heart disease surgical management. New York: Mosby ;1999. p. 221-8.

15. Sundt $3^{\text {rd }}$ TM, Camillo CJ, Mendeloff EN, Barner HB, Gay Jr. WA. Reappraisal of coronary endarterectomy for the treatment of diffuse coronary artery disease. Ann Thorac Surg 1999; 68:1272-7.

16. Ferraris VA, Harrah JD, Moritz DM, Striz M, Striz D, Ferraris SP. Long-term angiographic results of coronary endarterectomy. Ann Thorac Surg 2000; 69:1737-43.

17. Asimakopoulos G, Taylor KM, Ratnatunga CP. Outcome of coronary endarterectomy: a case-control study. Ann Thorac Surg 1999; 67: 989-93.

18. Gill IS, Beanlands DS, Boyd WD, Finlay S, Keon WJ. Left anterior descending endarterectomy and internal thoracic artery bypass for diffuse coronary disease. Ann Thorac Surg 1998; 65: 659-62.

19. Naseri E, Arsan S. Coronary endarterectomy on beating heart. Ann Thorac Surg 1999; 68:630-1.
20. Kragel AH, McIntosh CL, Roberts WC. Coronary arterial morphology 10 years after "endarterectomy". Clin Cardiol 1990; 13:224-6.

21. Walley VM, Byard RW, Keon WJ. A study of the sequential morphologic changes after manual coronary endarterectomy. J Thorac Cardiovasc Surg 1991; 102:890-4.

22. Chesebro JH, Fuster V, Elveback LR, Clements IP, Smith HC, Hoemes Jr. DR et al. Effect of dipyridamole and aspirin on late vein-graft patency after coronary bypass operations. N Engl J Med 1984; 310:209-14.

23. Dumanian V. Endarterectomy of the branches of the left coronary artery in combination with an aorta-to-coronary artery reversed saphenous vein graft. J Cardiovasc Surg (Torino) 1974;15:154-7.

24. Steinhubl SR, Tan WA, Foody JM, Topol EJ. Incidence and clinical course of thrombotic thrombocytopenic purpura due to ticlopidine following coronary stenting. JAMA 1999; 281:806-10.

25. Gol MK, Yilmazkaya B, Goksel S, Sener E, Mavitas B, Tasdemir $\mathrm{O}$ et al. Results of right coronary artery endarterectomy with or without patchplasty. J Card Surg 1999; $14: 75-81$.

26. Miller DC, Stinson EB, Oyer PE, Reitz BA, Jamieson SW, Moreno-Cabral RJ et al. Long-term clinical assessment of the efficacy of adjunctive coronary endarterectomy. J Thorac Cardiovasc Surg 1981; 81:21-9.

27. Alamanni F, Parolari A, Agrifoglio M, Valerio N, Zanobini M, Repossini A, et al. Myocardial revascularization procedures on multisegment diseased left anterior descending artery: endarterectomy or multiple sequential anastomoses (jumping)? Minerva Cardiol Angiol 1996; 44:471-7.

28. Mills NL. Coronary endarterectomy: surgical techniques for patients with extensive distal atherosclerotic coronary disease. Adv Card Surg 1998; 10:197-227. 